\title{
Uso de experimentos e aplicativos de análise de dados no ensino da $2^{a}$ Lei de Newtons
}

\author{
Rainner dos Santos Carvalho ${ }^{1}$, Miguel Justiniano Abanto Peralta², Isaías Fernandes Gomes ${ }^{3}$ \\ 1, 2, 3 Universidade Federal do Acre (UFAC)
}

Palavras-Chave: Ensino de Física, Experimentos, Tecnologia, Software.

\section{Introdução}

As Tecnologias de Informação e Comunicação estão cada dia mais presentes em nossas vidas, inclusive no meio de trabalho, com o pensamento que algo surge tecnologicamente para auxiliar e facilitar o desenvolvimento das tarefas, este trabalho visa qualidade no desenvolvimento de ensino. Visando isto, vale observar o que diz o GTE do Ministério da Educação, Brasil 2013:

"(...)embora considere importante a utilização de tecnologias de qualidade com vistas à melhoria da educação, alerta que o seu uso se torna desprovido de sentido se não estiver aliado a uma perspectiva educacional comprometida com o desenvolvimento humano, com a formação de cidadãos, com a gestão democrática, com o respeito à profissão do professor e com a qualidade social da educação" (BRASIL, 2013, p. 10).

Visto isso, vale ressaltar o compromisso com o desenvolvimento do aluno em seu meio escolar e social, assim como providenciar uma formação de qualidade. Diante disso, este trabalho baseia-se na teoria pedagógica sócio interacionista de Vygotsky realizando estudo prático em grupo e psicologia educacional de David Ausubel com foco nos conhecimentos prévios, como orientação pedagógica para aplicação desses recursos tecnológicos, visto que para segunda lei de Newton usa-se os conhecimentos da cinemática. Diante do exposto propomos uma metodologia que faz uso de vídeos de experimentos realizados em sala de aula e de aplicativos de análises de vídeos e dados como Tracker e Excel, respectivamente. O nosso propósito é estimular o estudo de Física no primeiro ano do ensino médio, retratando a segunda lei de Newton em seu cotidiano, através de análise de vídeos de experimentos relacionados ao tema. Expondo assim, que a física é importante para o conhecimento dos fenômenos em sua volta, distinguindo-se melhor os eventos naturais que o cercam. Contudo, o cerne desse trabalho constitui-se em denotar ao estudante de maneira agradável que é possível adquirir conhecimento sobre a disciplina através do software de vídeo e análise de dados relacionado aos fenômenos físicos. Adaptado de Pereira (2015, p.1).

\section{Metodologia e material}

A proposta, terá a seguinte sequência didática apresentada na tabela 1, para as turmas de primeiro ano do ensino médio no município de Rio Branco:

Tabela 1 - Procedimentos metodológicos

\begin{tabular}{|c|l|}
\hline Etapa & Sequência do procedimento didático \\
\hline $1^{\circ}$ & Ensino expositivo a respeito da segunda lei de Newton. \\
\hline $2^{ }$ & Aplicação de um questionário diagnóstico. \\
\hline $3^{\circ}$ & Apresentação das ferramentas de ensino: Experimentos e Tracker. \\
\hline $4^{\circ}$ & Ensino da segunda lei de Newton com o uso dos experimentos. \\
\hline $5^{\circ}$ & Demonstração com o uso do Tracker e Excel. \\
\hline $6^{\circ}$ & Experimento de aplicação da segunda Lei de Newton \\
\hline $7^{\circ}$ & Inserção no Tracker e Excel \\
\hline $8^{\circ}$ & Aplicação de um questionário de avaliação. \\
\hline
\end{tabular}

Fonte: Próprio autor 
Atividade 1: Experimento com trilho de ar

Esta atividade experimental, visa a comprovação da segunda Lei de Newton experimentalmente. Nesse experimento colocamos um objeto de massa conhecida, num trilho de ar, construído artesanalmente. O objeto é submetido a uma força, a qual podemos variar afim de estudar a dependência da sua aceleração em termos da força aplicada. Também mudamos a configuração do experimento, de tal forma que, a força aplicada é mantida num valor constante e a massa é variada, com o intuito de estudar a aceleração em termos da massa. Para a realização deste experimento são necessários os seguintes materiais: Trilho de ar, balão, roldana, fio de ceda, caixa de papelão plastificada, pesos e secador de cabelo.

Atividade 2: Experimento da Máquina de Atwood

Para a realização deste experimento que tem o objetivo de mostrar uma aplicação da segunda Lei de Newton, faz-se uso de três materiais, que são: Roldana, fio de ceda e pesos.

Em ambos experimentos, se determinará através do Tracker, a posição de um objeto em função do tempo, as tabelas de dados correspondentes a cada experimento serão exportadas ao Excel, com o qual faremos um ajuste dos dados a uma curva que represente o movimento. Com o ajuste realizado será inferido o valor da aceleração em cada experimento. No primeiro experimento será discutido, como a aceleração depende da massa e da força aplicada, o que resultará numa comprovação da segunda lei de Newton. No segundo experimento compararemos o valor da aceleração determinada experimentalmente com 0 valor calculado teoricamente. Todas as discussões serão finalizadas com alunos do primeiro ano do ensino médio. Os experimentos mencionados já foram testados pelos autores, mas, ainda não foram aplicados em sala de aula.

As atividades terão como foco a interação entre os alunos para fazer uso dos conhecimentos já adquiridos de cinemática e das ferramentas tecnológicas introduzidas, assim como a discussão dos fenômenos físicos estudados.

\section{Resultados esperados}

Tendo como objetivo principal proporcionar uma sequência didática utilizando experimentos e a tecnologia como auxilio no ensino e aprendizagem, como objetivo especifico, tornar o ensino relacionado a segunda lei de Newton visível através do experimento comprovando esta lei e o experimento de aplicação, utilizar o aplicativo Tracker com foco na segunda lei de Newton, manusear o Excel para obtenção de gráficos corrigidos e estimular o interesse dos alunos para a disciplina. Espera-se que esses recursos tecnológicos facilitem a compreensão da segunda lei de Newton.

\section{Referências}

AUSUBEL, D. P.; NOVAK, J. D.; HANESIAN, H. Psicologia Educacional, 2 ed. Rio de Janeiro: interamericana, 1980.

BRASIL. Guia de tecnologias educacionais da educação integral e integrada e da

articulação da escola com seu território, Ministério da Educação, Secretaria de Educação Básica, Brasília, 2013.

PEREIRA, D. V. O Ensino De Inércia Com Desenhos Animados, Utilizando Futurama Como

Ferramenta Lúdica. Mestrado, Universidade de Brasília, 2015.

VYGOTSKI, L. S., A Formação Social da Mente, 4. ed., São Paulo, Livraria Martins Fontes

Editora Ltda., 1991. 